Seventeenth Scientific Meeting-Eighth Scottish Meeting

Joint Meeting with the Food Group of the Society of Chemical INDUSTRY (GLASGOW SECTION)

Royal Technical College, Glasgow, NOVEMBER 6TH, 1943

\title{
DIET AND INDUSTRIAL HEALTH
}

\author{
Chairman, Mr. J. BRuCE
}

\section{Special Nutritional Needs of the Industrial Worker}

\author{
Dr. D. M. Watson (Stewart and Lloyd, Ltd., Coatbridge, Lanarkshire)
}

During the past century the health of our working classes, as a whole, has very considerably improved, but, thankful as we are for this sign of betterment, we still have many important contributions to make before we can, even in a modest manner, say that we are building up a healthy race or can feel confident of being within sight of the goal we are striving towards, that of overcoming those evils which have so long afflicted mankind or of adequately dealing with that malnutrition which has produced so many defectives and weaklings, past and present. There are so many intermixed, interwoven, attributable causes of ill health, that, even now, we are only beginning to realize the enormity of the task, as well as the magnitude of the opportunity, which lies ahead of us, for creating a fit and healthy race.

Although I fully appreciate how very imperfectly I can deal with the subject, I would like first to deal briefly with malnutrition; then with what I think are the nutritional needs for healthy living, before closing with some remarks on what I feel would be desirable and of benefit to workers in one of our heavy industries. To start with, may I then speak of some of the effects of inadequate nutrition.

Firstly, with reference to the adolescent, the health of our youth is, by itself, a definite problem, quite apart, in a way, from the problem of the adult. In the past we have seen communications from the Ministry of Health pointing out that the physical standard of our youth, that is, of those leaving school at 14 years of age, has a decided tendency to decline before they reach 18 or 20 years. This decline may be, to some extent, the result of too early contact with the work of industry, or the result, in a measure, of the withdrawal of that discipline which was a part of their school life, when they gain employment in industry.

Prior to 1938 there was no medical service, such as the National Health Insurance, for these youngsters until they reached 16 years of age. And we must remember that it is during these years, 14 to 16 , that their rate of growth quickens, necessitating extra nourishment, and that it is in this period of life that tuberculosis reaches its peak. We must recollect, too, that the invasion of tubercular disease before the age of 20 is very often due to the overstrain of work and malnutrition.

Generally speaking, the effects of inadequate nutrition on the adult are relatively less grave and less serious for, by the time adult life is 
reached, growth has stopped. But, because of the work on which he is engaged and from which he earns his wages, there are extra demands for energy producing foods, and for protective foods. Here, however, the earlier upbringing must be reckoned with; for the physical development of the adult and his health generally, depend very largely on the standard of nutrition during adolescence. If, from whatever reason, there has been a lack or deficiency in his dietary during that period, then we find him having attained adult life more defective, more stunted, and less resistant to the invasion of disease, than his fellow worker who had enjoyed the benefits of a fuller, richer, more complete diet during that dangerous period.

This was very definitely suggested by the results of the medical examination of over 2,000,000 men during the last war. From the reports issued, it would appear that between one-half and three-fifths suffered from disabilities of one kind or another, although only about one-tenth was unfit and in grade IV, suggesting that these disabilities might, conceivably, be largely due to some degree of malnutrition in earlier life.

Countless experiments have been made by numerous investigators into this great question of the effect of improved dietary on the health, wellbeing, and fitness of the individual. I would like to quote only one or two of these. We all know from past reports the very remarkable improvements in heights and weights of children who were given milk as an addition to their ordinary diet, when compared with children of a similar class and age who had not received this addition (Leighton and MoKinlay, 1930). I would like to recall too that experiment carried out by McCarrison in India some years ago (McCarrison, 1926). Working with two groups of rats, 20 in each group, he fed one group on a diet such as is used by the virile Sikhs of Northern India, and the other group on the poor quality food that was the main support of the poorer classes in the country. In the first group, that is the group on the richer diet, the rate of death, after 6 months, was only one-third of what it was in the other group. Further, McCarrison found that the main causes of death in the second group were respiratory, just as were the principal causes of death in the human beings on whose type of diet the second group was fed and, while the second group kept losing weight throughout the period, the first group showed steady gains in weight and size, and produced young.

Now, if we take it that food plays a very important part in building up health, what do we consider are the nutritional needs for health in the human being?

An adequate and properly balanced diet, while not so imperative for the adult as for the adolescent, must be fully maintained if a maximum standard of fitness is hoped for. This diet will naturally vary with age, occupation, climate and other external circumstances. The adequacy of a diet depends much more on quality than on quantity. To the energy producing foods, and these energy producing constituents are for the most part relatively speaking cheaper, there should be added certain protective foods, many of which are unfortunately more expensive. To get a really adequate diet we must have both so we cannot, to speak colloquially, do things on the cheap in the matter of food.

This brings us face to face with the fact that, to a large extent, the question is an economic one, dependent on the sufficiency of the workers' voL. 2, 1944] 
earnings to procure the quantity and quality of food required. One must of course admit, that there may be lack of care in making purchases and unwise spending. Here education, instruction and example, e.g., in canteen meals, in the proper selection of foodstuffs and the correct methods of their preparation, will be very much needed.

There are numerous standards for requirements with some of which we are all familiar. These do not usually differ much. Two points are specially to be noted: (1) a man engaged in heavy work needs from 30 to 60 per cent. more food than a man on light work, and (2) adolescents need nearly as much as a man on moderately heavy work. All should, in my opinion, have from 37 to $50 \mathrm{~g}$. animal protein daily.

As war time has imposed so many restrictions and rationing, we should very carefully study the proper selections of foodstuffs for our workers so that balanced meals can be provided.

Black out, fatigue and war strain are all tending to undermine the health of our working population. It has also been found that, even though a diet may be apparently adequate, if variety is lacking we begin to notice a decline in the fitness of the individual taking this type of menu. Unfortunately for us in this country, monotony of diet is very prevalent among industrial workers. This has tended to prejudice them against new foodstuffs or even against old foods in new guises, e.g., dried milk and dried egg.

Now that there is a quite considerable proportion of women in industry, and a very large number of our workers making use of canteen meals, I would suggest the employment of trained dieticians. The trained dieticians would be able to compose menus which would be adequate and balanced. They would be in a position to make the most of the foodstuffs available; they would be better able to see that the flavours of the foods were conserved, which is a problem in cooking for large numbers. With so many women in industry, the dieticians might, by giving hints and short lectures at the mealtime breaks, act as the guides who would show the mothers of today and tomorrow better ways of planning meals and of making the best use of the available foodstuffs.

For the adolescent $I$ would advocate trying the experiment of giving full meals at reduced cost, to ensure his getting a complete midday meal, at, say, half cost for those under 16 and three-quarters cost for those under 21. This, I feel, would reflect itself in improved development of our youth and, where there is a factory medical officer, careful check weighings could be taken at regular intervals.

I suggest this plan, for the carried meal has been one of the black spots in modern industry where, as so often is the case, adolescents live too far from their home to go there for their meal. Since April of this year, and at the request of the Ministry of Food, we have taken part in the Ministry's height and weight survey. We asked for volunteers from a cross section of our workers. These included office staffs, inspection groups, operatives and general labourers, males and females. We divided them into 2 age groups for males and for females: those under 21 years of age, and those in the age groups 21 to 60 .

We have had 3 weighings since April, the last one was in October, and we have been struck by the fact that, in almost all cases, where the personnel were taking advantage of the canteen, there was no loss of weight 
and in many cases decided gains. Many of the group that make their meal of tea and a carried lunch have shown decreases in weight. Difference in height was not so noticeable but one has to remember that the youths, male and female, are mostly now about 19 to 20 years of age.

TABLE 1

Percentage of "Carried" Luneh Group Showing Decrease in Wrieht

\begin{tabular}{l|c|c|c|c}
\hline \multirow{4}{*}{ Age group } & \multicolumn{2}{|c|}{ Women } & \multicolumn{2}{|c}{ Men } \\
\cline { 2 - 5 } & $\begin{array}{c}\text { Approx. average } \\
\text { age } \\
\text { years }\end{array}$ & Per cent. & $\begin{array}{c}\text { Approx. average } \\
\text { age } \\
\text { years }\end{array}$ & Per cent. \\
\hline $\begin{array}{l}\text { Under } 21 \\
21 \text { to } 60\end{array}$ & 19 & 23 & 19 & 7 \\
\hline
\end{tabular}

If extra milk were available, I would like each worker, especially the younger workers, to have it added to the diet, in one form or another. Dried milk could be used in many ways.

Now as to the canteen itself: it should be convenient, bright, cheerful and congenial; it should be without the workers' actual workshop area to allow a short walk and fresh air; it should have convenient and adequate wash up facilities; the furniture should be well planned, the chairs comfortable; the tables should have tops of some heat resisting, clear, plastic material; the food should be served by a trolley service. If a dietician were employed there would probably be a set, balanced meal for all and therefore less likelihood of the worker choosing wrong dishes than if there was a choice. The meals for night shift workers should be run on similar lines but with the necessary alterations to suit night time requirements.

Many of these hopes will, I fear, have to wait until after the war for their fulfilment; but $I$ think that when happier times arrive we may look for improved canteen facilities helping towards better time keeping, less sickness and a generally improved standard of fitness in our workers.

Improvement in the physical standard of our workers will surely show its reward in a reduced accident rate. So much is being made of rehabilitation services just now, and very properly so, that I feel we would be justified in hoping that the workers' fitness will be considered also before accident or sickness occurs. And if these do occur then, being in a sound state of health before, the workers will respond the more quickly to rehabilitation.

\section{REFERENCES}

Leighton, G. and McKinlay, P. L. (1930). Milk Consumption and the Growth of Schoolchildren. Edinburgh: H.M.S.O.

McCarrison, R. (1926). Brit. med. J. ii, 730. 


\title{
Canteens from the Management's Point of View
}

\author{
Mr. F. Beattie and Mr. H. C. Moir (Beatties Ltd., Dennistoun, \\ Glasgow, E.1)
}

At the outset, in order to give background to the observations which follow, it is perhaps desirable to emphasize the fact that the baking trade differs in many respects from most other industries and that the point of view of the directorate and management of baking establishments is of necessity coloured by the circumstances and needs of their own trade.

The first point to note is that, up till now, most of the baking is done at night or in the early morning, in fact, baking is a round the clock business. In consequence, bakers and bakery workers have had practically no facilities for obtaining meals outside their place of employment, either in restaurants or their own homes, even if these were adjacent to their place of employment, because of the awkward times at which their meal breaks occurred. Secondly, because of the nature of the work, the meal break is restricted to half an hour in the case of bakers and not more than one hour in the case of ancillary workers. This short period obviously does not allow much time to change from working to outdoor clothes, go out for a meal, come back and change back from outdoor to working clothes and indeed, the rapid change from working at the ovens to outside winter temperature would be dangerous to health. Thirdly, the nature of the work is such that it is difficult, if not impossible, in many cases to forecast the exact time at which a break can be made and this fact is recognized by agreement with the Trade Union that the break must not be earlier than 3 hours or later than 5 hours after starting. Further, the starting times, and consequently meal times, of various workers are staggered according to the part of the process on which they are employed. Consequently, the workers in an entire department or section can rarely synchronize their breaks so as to allow of definite catering arrangements.

The position as it was in the past can be illustrated by reference to our own bakery in Dennistoun. A mess room of sorts was provided in which the men could eat their meals, but there were practically no arrangements for cooking. Fortunately, in a bakery there are always ovens available, officially or otherwise, and the men brought in food to be cooked, a bit of fish, sausages, kippers, steak and onions, pies, and so on, and cooked them, often surreptitiously, in a corner of the oven along with a batch of bread. Those who know just how easily bread picks up taints will appreciate the feelings of the management if onions or kippers happened to be a popular choice. Tea was prepared somehow, often by boiling a can of water over the "chaffer" of the Scotch ovens, and jelly jars or empty fruit tins, served as drinking vessels. "Fingers were made before forks" was the accepted motto and, altogether, the whole position was very unsatisfactory. It is probable that similar conditions obtain in many of the smaller bakeries to this day. 
The founder of the firm, himself a practical baker, decided that this could not go on and in 1910 established a canteen and, incidentally, at the same time put in baths for the use of the workers. At that time no females were employed. A male cook was employed to prepare the food brought by the workers. Crockery and cutlery were furnished and tea sold by the mugful. Each man as he arrived to start his night's work handed his eggs or sausages or fish or bacon or whatever he had to the cook and gave him an idea of the approximate time at which he expected to break for his meal. The cook had a pigeonhole system for "Giling" the various items, but the system, though an improvement on the previous lack of system, was not a success, and was finally discarded in 1922 and a proper canteen built and equipped on modern lines. By this time the bakery had expanded considerably and increasing numbers of girls were employed during the day. The canteen was then made to serve both day and night shifts. As the bakery has expanded, the canteen has naturally expanded with it, and as the scope of the firm has widened, bringing in other factories, so has our experience of the benefits of canteens increased and the opinions expressed can be taken as the result of experience of four canteens under our control.

During the 20 odd years of its existence, many changes have taken place and many different schemes have been tried. Indeed a completely new canteen has been established. Plans were in being just before the war for a very elaborate extension including rest rooms and roof winter garden, all adjacent. The outbreak of war prevented their materialization, but it is the intention of the directors that these plans will be executed at the earliest possible moment. The present system of operation is that which has been evolved as the result of long and wide experience and is based on no doctrinaire decisions. The canteens at our 2 main factories come under the control of the Welfare Supervisor. The firm provides accommodation, heat, light, gas, equipment and wages. The prices paid for meals, therefore, cover cost of food only and consequently are very low. There is in each canteen a manageress and the kitchen staff necessary to overtake the work. In peace time there were also a few waitresses to attend the tables, but now with shortage of labour the cafeteria system is employed.

In order to ensure absolute equity, all grades of employees use the same canteen, and are served at the same bar. That is, there are no separate rooms for directors, managers or staff. There is thus no possibility of grumbling that the best of the rations, for instance, go to the "heads" since the service is open for all to see. Apart from removing any cause for grumbling, this system has the important result of ensuring that the supplements to the normal civilian rations permitted by the Ministry of Food find their way to the people for whom they are intended.

Each dish is separately served and priced, so that workers can select such meals as they choose, and payment is direct. No endeavour is made to provide a fixed price dinner or breakfast and the use of priced tokens has been discarded. The canteen is open day and night throughout the week, the only time at which it is closed being from 5 p.m. till 10.30 p.m. on Saturdays. At any time of the day or night, therefore, employees can obtain a hot meal in comfort and in pleasant surroundings.

voL. 2,1944 ] 
The directors are obviously convinced that the provision of canteen facilities is essential to the efficient conduct of the business. Unfortunately, statistics are not available to demonstrate the benefits accruing from the provision of canteens either at Dennistoun, where the canteen is long established, or at other factories where the canteens are of more recent date. We did endeavour to obtain statistics from one factory where the canteen was established within the past few years but the impact of zoning, concentration and rationing schemes, the call up of men and women, and so on, completely invalidated the figures which were available. However, certain general conclusions can be drawn. There is no doubt whatever that the general health of employees benefits considerably, with consequent reduction of absenteeism. This, of course, is accounted for, partly by the fact that more varied and better balanced meals are eaten than was possible in the old days, and partly by the fact that there is not the same temptation to rush home and bolt a meal during the short meal break on the part of those whose hours of work permit them to do so. In the case of married women employed part time in particular, and also of young persons whose mothers are at work whole or part time, the possibility of obtaining well cooked meals at reasonable cost makes all the difference. Further, we find that the provision of canteens does help to reduce labour turnover. Other things being equal, employees of all grades prefer working in an establishment where there is a canteen to one where they have to carry a packed lunch and drum up a cup of tea over a gas ring in some odd corner. The general morale of the factory too is improved, with consequent beneficial effects on production. When overtime is needed, and in the baking trade the necessity for overtime often arises without warning, we find it a very great advantage to be able to send the unfortunates who have to work past their time for an extra meal to fit them for their extra work.

Other advantages, such as cleanliness of the factory, are without the scope of this paper.

Incidentally, we find that most of the advantages mentioned above apply with about equal force to a canteen serving 600 to 700 main meals and breakfasts per day and to one serving only 50 to 60 main meals.

Dealing with more technical aspects of nutrition, there are some points worthy of note. We are well aware of recent advances in nutritional knowledge; in fact, our laboratory must of necessity keep abreast of this subject and has indeed helped to contribute to it. It is largely in consequence of this knowledge that the decisions were taken which permit meals to be sold at minimum prices. It has already been stated that all costs of the canteen, apart from food, are borne by the firm and, consequently, the meals are purveyed at such low prices that even the poorest paid employee can afford to purchase a nutritious meal. Further, knowing the importance of freshness in vegetables, we have arranged that, as far as possible, vegetables are supplied direct from the directors' gardens. In one factory where space is available the canteen is surrounded by its own kitchen garden, and vegetables go direct from the garden to the pot or the table. Fruit juices are still supplied when they are available and every encouragement is given to the consumption of the so called protective foods. With a 24 hour service we find that breakfasts 
are in demand from 5 a.m. till 10.30 a.m., dinners from 10.30 a.m. till 3.30 p.m., high teas or suppers from 4 p.m. till 5 a.m. With this spread over of meals it will be appreciated that the admittedly pernicious practice of keeping hot must be adopted. As far as is practicable potatoes are boiled in relays and vegetables and other dishes prepared as required but, particularly under war time conditions, this cannot be done as one would like and the consequent loss of vitamin $\mathrm{C}$ from the potatoes, for example, while it is deplored, cannot be avoided. This point can be elaborated a little further. The staff is cut by the Ministry of Labour below what we think is the minimum required. At certain times squads of workers with only half an hour's break arrive in the canteen and all hands must be available to serve them. The result is that sufficient food must be cooked beforehand to permit the staff available to keep the service going, with a series of such squads, until a known break, when some of the staff can go back to cooking and the remainder can serve the lessened flow of traffic. In practice this means that usually two or three lots of potatoes are made to cover a five hour period.

The provision of balanced meals or of foodstuffs to supply those nutritional requirements not likely to be met by the normal diet is one of great difficulty and one to which we do not see the solution. In the first place we find that the majority of the employees are exceedingly conservative in their food habits. Even under war conditions many will not accept, for example, rabbit. Unusual vegetables such as parsnips are not accepted and, if used in stews, are simply left on the side of the plate. Doubtless persistence would ultimately change these things, and it is pleasant to record that salads are exceedingly popular and that milk, when it was available, was drunk in increasingly large quantities. It is perhaps worthy of note that the popular salads consist of lettuce, with or without tomato, and bectroot. The introduction of grated carrot, shredded cabbage, or celery, is not greeted with enthusiasm and, in general, any attempt to force any item of diet on the workers is regarded with suspicion and usually leads to waste. The position with regard to young persons presents several difficulties. Firstly, they are usually the lowest paid and, in spite of the low prices, may feel unable to afford a full meal, or, at any rate, they prefer to make do with the minimum during working hours and rely on getting their bellies filled at home and so save their money for other purposes. In many cases, particularly with girls, the parents allocate sufficient money daily for a good meal, but some individuals prefer to spend part of the allocation on a bottle of "pop" or in some cases on cigarettes to the detriment of their diet. Cod liver oil and malt extract is made available free to all under 21 who desire to take it and the Welfare Supervisor and nurses endeavour to persuade those who appear to need guidance to take good meals and this supplement, but in many cases without result. Many take soup and a sweet, or potatoes and gravy and a sweet; chips are always in demand, and a very popular combination is chips and beetroot. Milk puddings are very popular and, of course, under war time conditions anything sweet vanishes like snow in sumner. This problem is still unsolved but a meal consisting of a plate of scotch broth and a milk pudding is certainly preferable to bread and "marge" and tea, even if it is not ideal. The

vot. 2,1944$]$ 
provision of fixed price dinners, particularly if they were subsidized for young people, might lead to an improvement, but for a great variety of reasons we have found this impracticable.

We have not mentioned the difficulties of rationing. Much as we would like to provide those foods most necessary to supplement the normal diet under present day conditions, as you are all aware, we can provide only what we can obtain. 